OPEN ACCESS

Edited by:

Zhenhai Chen,

Yangzhou University, China

Reviewed by:

Kuldeep Dhama,

Indian Veterinary Research Institute

(IVRI), India

Santhamani Ramasamy,

Albert Einstein College of Medicine,

United States

${ }^{*}$ Correspondence: Jizhang Zhou

zhoujizhang@caas.cn

Specialty section:

This article was submitted to Veterinary Infectious Diseases,

a section of the journal

Frontiers in Veterinary Science

Received: 20 December 2017

Accepted: 06 April 2018

Published: 30 May 2018

Citation:

Zhou J, Li Z, Lou Z and Fei Y (2018) Prevalence, Diagnosis, and Vaccination Situation of Animal

Chlamydiosis in China.

Front. Vet. Sci. 5:88.

doi: 10.3389/fvets.2018.00088

\section{Prevalence, Diagnosis, and Vaccination Situation of Animal Chlamydiosis in China}

\author{
Jizhang Zhou*, Zhaocai Li, Zhongzi Lou and Yuanyuan Fei \\ State Key Laboratory of Veterinary Etiological Biology, Lanzhou Veterinary Research Institute, Chinese Academy of \\ Agricultural Sciences, Lanzhou, China
}

Since the first case of Chlamydia infection in duck had been reported in 1956 and the first case from domestic animal had been reported in 1979 in China, the chlamydia prevalence in China was heavily according to the published data. The Chlamydia in avian prevalence has been reported at least 11 provinces, Chlamydia in sheep and goats at least 11 provinces, in swine at least 15 provinces, in cows at least 13 provinces and in yaks at least 5 provinces with result of IHA detection. Different diagnostic method such as CFT, ELISA and ABC-ELISA (avidin-biotin-complex ELISA) had been established besides IHA. The inactivated vaccines have been developed with isolated strains from sheep, goats, swine and cows. These inactivated vaccines have been used since 1980s and Chlamydia prevalence in China has been successfully controlled in domestic animal. However, the inactivated vaccines of Chlamydia isolated from avian species have not been successful, although a series of experimental vaccine have been done. Due to the unsustainable eradication plan of Chlamydia in China, sporadic outbreak in animal would happen if the vaccinations were suspended and economy lose in some farmers. Although Chlamydia prevalence in China has a long history, however, almost all published studies are in Chinese, which, in some degree, blocked scientists in other countries to understand the prevalence situation and control measures of Chlamydia in China.

Keywords: prevalence, diagnosis, vaccine, Chlamydia, China

\section{INTRODUCTION}

Chlamydiae, zoonotic and obligate intracellular Gram-negative bacteria, have a worldwide distribution and cause a wide range of diseases in human hosts, livestock, companion animals, wildlife, exotic species (1), and poultry (2). Chlamydiosis, a disease caused by Chlamydia, has been found in many countries around the world where sheep-rearing is practiced, ranging from Europe to Africa, North America (3), and Asia (4). These include France (5), Poland (6), Spain (7), Australia (8), the United Kingdom (9), Ireland (10), China (11) and Switerland (12).

Vaccination is one of the best ways to control Chlamydiosis. Formalin-inactivated, egg-grown vaccine of Chlamydia abortus was developed (13) in the U. K. The inactivated vaccine of C. abortus was used in sheep although the efficacy of the vaccine against EAE was unstisfatory (14). After the first reported cases of avian Chlamydia in China in 1959 (15) and reports of infection in domestic animals in Qinghai province in 1981 (4), China began developing inactivated vaccines using different isolates from sheep, swine, and cow, which successfully controlled the prevalence 
of Chlamydia in China. However, almost all these achievements were reported only in Chinese, rather than in English, which presents a challenge for scientists all over the world to understand the situation of Chlamydia prevalence and control measures in China.

\section{CHLAMYDIA PREVALENCE}

Following the first report of Chlamydiosis in China from a duck in Beijing in 1959 (15), prevalence of avian Chlamydia has been reported in 10 provinces, including Beijing, Tianjin, Jiangsu, and Guangdong due to lack of effective vaccines (16).
The first instance of livestock Chlamydiosis was found in ruminants in the Qinghai province by scientists from the Lanzhou Veterinary Research institute (LVRI), Chinese Academy of Agricultural Sciences (CAAS), in 1979(17). Chlamydia was detected in sheep and goats in at least 11 provinces, in swine in 15 provinces, in bovines in 13 provinces, and in yaks in 5 provinces, using the indirect hemagglutination assay (IHA) test; this prevalence if the disease caused a huge economic loss in China (Figure 1). Although the seropositive rate was high in different animals in China, similar seropositive rates existed in other countries. For example, a German study reported Chlamydia antigen prevalence in sheep to range between 5 and $71 \%$ (18) and a Polish study reported the prevalence of Chlamydial infection in birds in Europe to range between 6.3

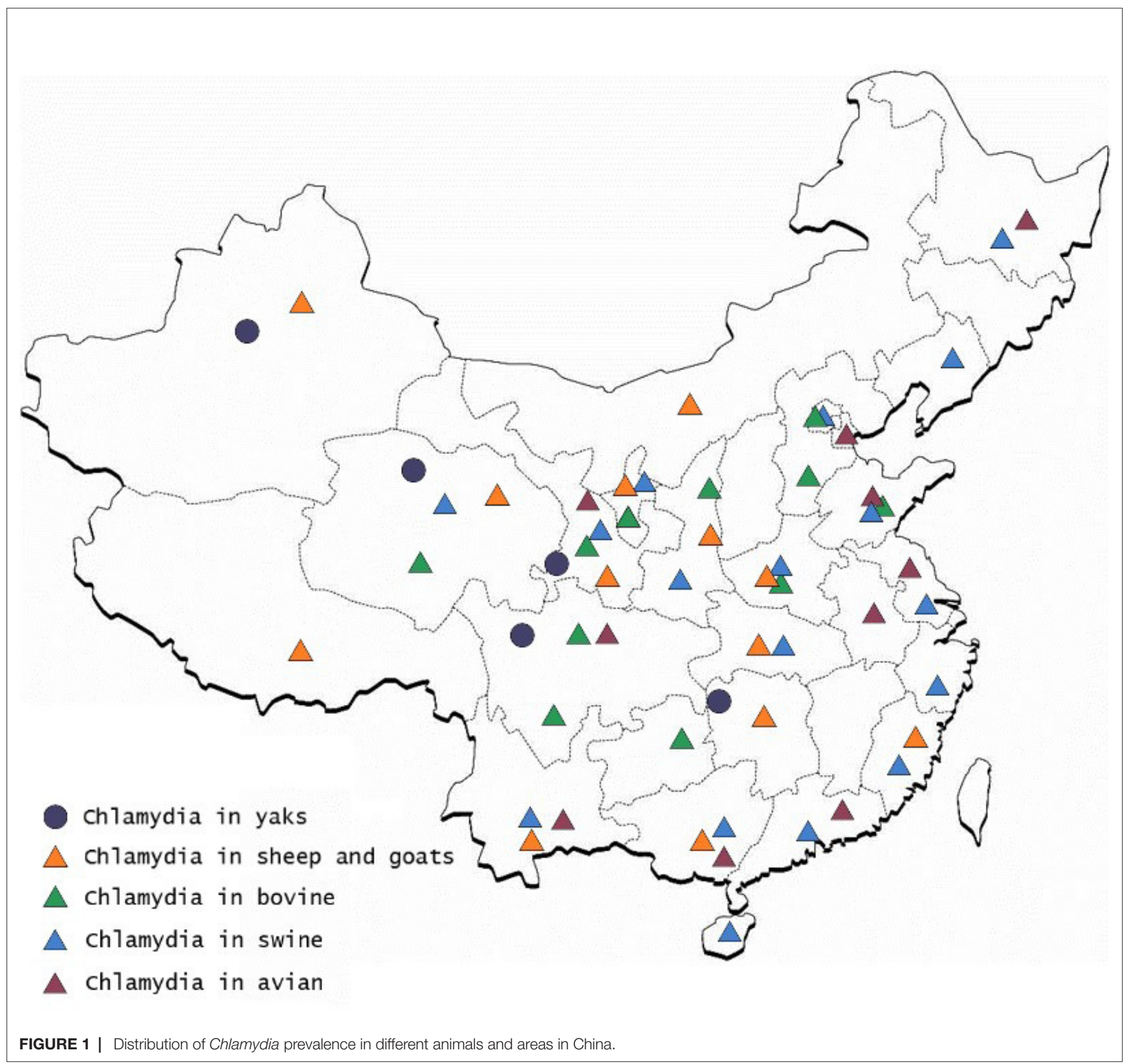


TABLE 1 | Avian Chlamydia seroprevalence in China.

\begin{tabular}{llll}
\hline Year & $\begin{array}{l}\text { Positive } \\
\text { rate }\end{array}$ & Area & $\begin{array}{l}\text { Reference (published in } \\
\text { Chinese) }\end{array}$ \\
\hline $\mathbf{1 9 9 1}$ & $21.8 \%$ & Shandong & Wu et al. (1990:61) (23) \\
$\mathbf{1 9 8 8 - 1 9 8 9}$ & $39.2 \%$ & Sichuan & $\begin{array}{l}\text { Xu et al. (1991:18-19) (24) } \\
\mathbf{1 9 9 1}\end{array}$ \\
$\mathbf{1 9 9 4}$ & $26.91 \%$ & Gansu & Wang et al. (1991:18) (25) \\
$\mathbf{1 9 9 4}$ & $22.7 \%$ & Jiangsu & Yu et al. (1994:13-15) (20) \\
$\mathbf{1 9 9 8}$ & $5.1 \%$ & Heilongjiang & Jiang et al. (1998:25-6) (27) \\
$\mathbf{2 0 0 1}$ & $20.66 \%$ & Guangxi & Liu et al. (2001:13) (28) \\
$\mathbf{2 0 0 3}$ & $10-30 \%$ & Beijing Tianjin & Shi et al. (2003:217-21) (21) \\
$\mathbf{2 0 0 3}$ & $59.9 \%$ & Guangdong & Zhang et al. (2003:29) (29) \\
$\mathbf{2 0 1 2}$ & $20-45.4 \%$ & Anhui & Ou et al. (2012:61-3) (30) \\
$\mathbf{2 0 1 3}$ & $3.9 \%$ & Qinghai & Ma et al. (2013:213-5) (31) \\
$\mathbf{2 0 1 2 - 2 0 1 4}$ & $36.97 \%$ & Tianjin & Zhu et al. (2016:148-50) (32) \\
$\mathbf{2 0 1 6}$ & $43.2 \%$ & Sichuan & Ouyang et al. (2016:46-51) (22) \\
\hline
\end{tabular}

and $19.2 \%$ (19). There was uncertainty about the accuracy of the results of Chlamydia detected in animals using the IHA technique in China. However, compared with the results from other countries, which used McCoy cell culture isolation, the IHA technique may reflect the real prevalence of Chlamydia in China.

Using IHA, Chlamydia was found to be prevalent in chicken, ducks, pigeons, geese, and other avian species in 11 provinces, with seropositive rates of 10 to $60 \%$ in last three decades $(20-$ 22) (Table 1). Likewise, Chlamydia was prevalent in cows, yaks, sheep, goats, and pigs with seropositive rates of $2-40 \%$ in goats and sheep (4, 33-38) (Table 2), 5-53\% in swine (50-55) (Table 3), $3-35 \%$ in bovine (67-71) (Table 4), and $2-30 \%$ in yak (11, 76-79) (Table 5). The disease was found in almost the entire country through IHA detection.

TABLE 2 | Sheep and goat Chlamydia seroprevalence in China.

\begin{tabular}{|c|c|c|c|}
\hline Year & $\begin{array}{l}\text { Positive } \\
\text { rate }\end{array}$ & Area & $\begin{array}{l}\text { Reference (published in } \\
\text { Chinese) }\end{array}$ \\
\hline 1981 & & Qinghai & Yang et al. (1981:13-15) (4) \\
\hline 1987-1989 & $6.9 \%$ & Zhejiang & Wang et al.(1990:11) (39) \\
\hline 1988-1989 & $2.95 \%$ & Hubei & Zhang et al. (1992:34) (40) \\
\hline 1998 & $5.78 \%$ & Hunan & Qiu et al.(1998:3-5) (41) \\
\hline 1996-1998 & $1.98 \%$ & Guangxi & Wu et al. (2000:41) (36) \\
\hline 1991-1995 & $26.12 \%$ & Yunan & Wang et al. (2000:465-6) (42) \\
\hline 2003 & $19.3 \%$ & Ningxia & Bao et al. (2003:13-14) (43) \\
\hline 2009 & $7.57 \%$ & Neimeng & Wang et al. (2009:154) (44) \\
\hline 2010-2011 & $36.12 \%$ & Guizhou & Hong et al. (2012:127-9) (37) \\
\hline 2012 & $1.4 \%$ & Xinjiang & Lei et al. (2012:28-9) (45) \\
\hline 2013 & $20.9 \%$ & Xizang & $\begin{array}{l}\text { Huang et al. (2013:243-5) (in } \\
\text { English) (46) }\end{array}$ \\
\hline 2014 & $40.3 \%$ & Qinghai & Zhang et al. (2014:38-9) (47) \\
\hline 2014 & $60 \%$ & Hubei & Cheng et al. (2015:472-4) (48) \\
\hline 2014 & $42.86 \%$ & Anhui & Cheng et al. (2015:472-4) (48) \\
\hline 2014 & $52.75 \%$ & Shandong & Cheng et al. (2015:472-4) (48) \\
\hline 2014 & $40.13 \%$ & Xinjiang & Cheng et al. (2015:472-4) (48) \\
\hline 2014 & $51.91 \%$ & Jilin & Cheng et al. (2015:472-4) (48) \\
\hline 2014 & $30.56 \%$ & Sichuan & Cheng et al. (2015:472-4) (48) \\
\hline 2014 & $67.74 \%$ & Ningxia & Cheng et al. (2015:472-4) (48) \\
\hline 2014 & $90 \%$ & Gansu & Cheng et al. (2015:472-4) (48) \\
\hline 2012-2015 & $13.09 \%$ & Qinghai & Su.(2016:29-30) (35) \\
\hline 2015-2016 & $12.5 \%$ & Henan & Gao et al. (2017:66-9) (49) \\
\hline 2013-2017 & $11.87 \%$ & Qinghai & Zha et al. (2017:60-1) (38) \\
\hline
\end{tabular}

TABLE 3 | Swine Chlamydia seroprevalence in China.

\begin{tabular}{|c|c|c|c|}
\hline Year & $\begin{array}{l}\text { Positive } \\
\text { rate }\end{array}$ & Area & $\begin{array}{l}\text { Reference (published in } \\
\text { Chinese) }\end{array}$ \\
\hline 1983-1984 & $29.72 \%$ & Hubei & Jiang et al. (1985:32-4) (50) \\
\hline 1985 & $33.3 \%$ & Qinghai & Diao et al. (1990:21-2) (56) \\
\hline 1991 & $20.4 \%$ & Guangxi & Yi et al. (1991:6-9) (55) \\
\hline 1997 & $13.65 \%$ & Shandong & Ji et al. (2003:39) (57) \\
\hline 1998-2000 & $34.91 \%$ & Gansu & Gao et al. (2001:13-14) (58) \\
\hline 2003 & $2.3 \%$ & Henan & Lang et al. (2004:29) (59) \\
\hline 2003 & $5.16 \%$ & Liaonin & Wang (2004:26) (60) \\
\hline 2005 & $49.49 \%$ & Hainan & Suo et al. (2005:31-2) (51) \\
\hline 2005 & $41.41 \%$ & Shanghai & Jin et al. (2005:23) (61) \\
\hline 2005 & $6.82 \%$ & Zhejiang & Jin et al. (2005:23) (61) \\
\hline 2004-2006 & $14.97 \%$ & Guangdong & Zhu et al. (2007:26-7) (62) \\
\hline 2006-2007 & $27.71 \%$ & Fujian & Zhou et al. (2008:30-5) (63) \\
\hline 2011 & $18.5 \%$ & Yunnan & Bi et al. (2011:134-6) (52) \\
\hline 2012 & $7.6 \%$ & Shaanxi & Wang et al. (2013:9-10) (64) \\
\hline 2013 & $53.30 \%$ & Qinghai & Ma et al. (2013:213-5) (31) \\
\hline 2014 & $58.59 \%$ & Jiangxi & Jang et al. (2014:27-28) (65) \\
\hline 2014 & $57.0 \%$ & Qinghai & Zhang et al. (2014:38-9) (47) \\
\hline 2014 & $18.88 \%$ & Yunnan & Li et al. (2014:29-30) (66) \\
\hline 2015 & $18.4 \%$ & Yunnan & Su et al. (2015:155-6) (53) \\
\hline 2013-2015 & $11.3 \%$ & Henan & Ma et al. (2016:119-22) (54) \\
\hline
\end{tabular}

\section{DIAGNOSTIC METHOD}

Before 1984, antibodies to Chlamydia were detected by using the complement fixation (CF) method in China. However, this technique was cumbersome and time consuming (88). Thus, a new technique, IHA, was developed. The IHA technique had a higher sensitivity and specificity than $\mathrm{CF}$, and has been used to determine the prevalence of Chlamydia in domestic animals in China since the 1980s (88). It has also been used as a high throughput method of seroprevalence detection. Positive results are detectable within $2 \mathrm{~h}$, but false positive and negative readings are possible, since scoring is subjective to the researcher's observation (88). Besides

TABLE 4 | Bovine Chlamydia seroprevalence in China.

\begin{tabular}{llll}
\hline Time & $\begin{array}{l}\text { Positive } \\
\text { rate }\end{array}$ & Area & Published in original journal \\
& $26.81 \%$ & Hubei & Yang et al. (1988:5-6) (72) \\
$\mathbf{1 9 8 8}$ & $16.13 \%$ & Shandong & Zhou et al. (2000:14-15) (67) \\
$\mathbf{1 9 9 7 - 1 9 9 8}$ & $23.1 \%$ & Hebei & Zhou et al. (2000:14-15) (67) \\
$\mathbf{1 9 9 7 - 1 9 9 8}$ & $43.18 \%$ & Shaanxi & Zhou et al. (2000:14-15) (67) \\
$\mathbf{1 9 9 7 - 1 9 9 8}$ & $25.71 \%$ & Henan & Zhou et al. (2000:14-15) (67) \\
$\mathbf{1 9 9 7 - 1 9 9 8}$ & $20.68 \%$ & Gansu & Zhou et al. (2000:14-15) (67) \\
$\mathbf{1 9 9 7 - 1 9 9 8}$ & $25.6 \%$ & Sichuan & Zhou et al. (2000:14-15) (67) \\
$\mathbf{1 9 9 7 - 1 9 9 8}$ & $16.8 \%$ & Ningxia & Zhou et al. (2000:14-15) (67) \\
$\mathbf{1 9 9 7 - 1 9 9 8}$ & $15.49 \%$ & Qinghai & Zhou et al. (2000:14-15) (67) \\
$\mathbf{1 9 9 7 - 1 9 9 8}$ & $24.14 \%$ & Ningxia & Xie et al. (2012:102-4) (68) \\
$\mathbf{2 0 1 2}$ & $2.86 \%$ & Guizhou & Hong et al. (2012:127-9) (37) \\
$\mathbf{2 0 1 0 - 2 0 1 1}$ & $21.3 \%$ & Chongqing & Huo (2013:67) (73) \\
$\mathbf{2 0 1 3}$ & $26.4 \%$ & Qinghai & Ma et al. (2013: 213-5) (31) \\
$\mathbf{2 0 1 3}$ & $17.71 \%$ & Gansu & Tan et al. (2015:1283-7) (74) \\
$\mathbf{2 0 1 3}$ & $38.97 \%$ & Ningxia & Tan et al. (2015:1283-7) (74) \\
$\mathbf{2 0 1 3}$ & $36.8 \%$ & Qinghai & Zhang et al. (2014:38-9) (47) \\
$\mathbf{2 0 1 4}$ & $8.25 \%$ & Qinghai & Su.(2016:29-30) (35) \\
$\mathbf{2 0 1 2 - 2 0 1 5}$ & $26.31 \%$ & Qinghai & Wang et al. (2016:16-17) (69) \\
$\mathbf{2 0 1 5}$ & $37.43 \%$ & Henan & Li et al. (2017:22-4) (71) \\
$\mathbf{2 0 1 5}$ & $1.75 \%$ & Qinghai & Chen et al. (2017:33-5) (75) \\
$\mathbf{2 0 1 5 - 2 0 1 6}$ & $9.13 \%$ & Qinghai & Zha et al. (2017:60-1) (38) \\
$\mathbf{2 0 1 3 - 2 0 1 7}$ & & &
\end{tabular}


TABLE 5 | Yak Chlamydia seroprevalence in China.

\begin{tabular}{llll}
\hline Year & $\begin{array}{l}\text { Positive } \\
\text { rate }\end{array}$ & Area & $\begin{array}{l}\text { Reference (published in } \\
\text { Chinese) }\end{array}$ \\
\hline $\mathbf{1 9 8 8}$ & $29.0 \%$ & Qinghai & Shuai et al. (1988:76-81) (76) \\
$\mathbf{1 9 9 3}$ & $21.03 \%$ & Qinghai & Dong et al. (1993:25) (80) \\
$\mathbf{1 9 9 6}$ & $2.1 \%$ & Xinjiang & Wang et al. (1996:46) (77) \\
$\mathbf{2 0 0 0}$ & $20.69 \%$ & Gansu & Zhou et al. (2000:14-15) (67) \\
$\mathbf{2 0 0 0}$ & $15.49 \%$ & Qinghai & Zhou et al. (2000:14-15) (67) \\
$\mathbf{2 0 0 0}$ & $25.6 \%$ & Sichuan & Zhou et al. (2000:14-15) (67) \\
$\mathbf{2 0 0 4}$ & $19.23 \%$ & Qinghai & Ma et al. (2004:14) (81) \\
$\mathbf{2 0 0 9}$ & $9.81 \%$ & Qinghai & Zhang et al. (2009:14-15) (82) \\
$\mathbf{2 0 1 0}$ & $17.39 \%$ & Qinghai & Hou(2011:10) (78) \\
$\mathbf{2 0 1 0 - 2 0 1 2}$ & $2.8 \%$ & Qinghai & Kong et al. (2012:51-51) (83) \\
$\mathbf{2 0 1 2}$ & $4.13 \%$ & Qinghai & Li et al. (2013:126) (84) \\
$\mathbf{2 0 1 3}$ & $27.7 \%$ & Qinghai & Xie(2013:33) (85) \\
$\mathbf{2 0 1 2 - 2 0 1 3}$ & $15.9 \%$ & Gansu & Qin(2015:8) (in English) (79) \\
$\mathbf{2 0 1 4}$ & $25.08 \%$ & Gansu & Yin(2014:281-285) (86) \\
$\mathbf{2 0 0 9 - 2 0 1 4}$ & $7.68 \%$ & Qinghai & Fu et al. (2016:50-51) (87) \\
$\mathbf{2 0 1 5}$ & $23.81 \%$ & Qinghai & Li et al. (2015:1-6) (in English) (11) \\
\hline
\end{tabular}

IHA, enzyme linked immunosorbent assay (ELISA) (89) and avidin-biotin-complex ELISA (ABC-ELISA) (90) techniques were developed. Although the ABC-ELISA and ELISA methods have higher sensitivity than the IHA method, they have not been used in clinical studies due to high cost.

For pathogen diagnosis, chicken egg isolation and Giemsa staining were combined to detect Chlamydia. The yolk sac membranes from dead chicken embryos were spread on slides and fixed with methanol or through heating, and Giemsa stain was used to stain them for half an hour or overnight. Chlamydia elementary body (EB) and inclusion were detected by light microscopy (91).

The PCR and real-time PCR tests, although highly sensitive and used to detect Chlamydia in different animals in other countries (92-96) have seldom been used on a large scale due to high cost. The ompl gene, which is very conservative, was used as a target gene to detect Chlamydia in different animals when IHA results were ambiguous $(16,97)$. In China, the PCR-RFLP method was developed and used only to identify Chlamydia species isolated from animals (11), while recombinase polymerase amplification (RPA) was used to identify C. abortus (98). However, IHA is considered as a simple, safe, and reliable means of testing $C$. abortus antibodies, and has been employed in previous serological investigations $(79,99)$.

\section{PREVENTION AND CONTROL OF CHLAMYDIOSIS}

\section{Vaccination}

Vaccination is one of the most important methods of disease prevention in animals. The inactivated vaccine of $C$. abortus plays a huge role to control the spreading of the disease in China. Simply, the process for developing inactivated vaccine is as follows: Chlamydia seeds were isolated from the yolk sac membranes of 7-day-old chicken embryos between the 4 and 8th days after inoculation. The titer of Chlamydia used for vaccines was at least $10^{12} \mathrm{ELD}_{50} / 0.4 \mathrm{ml}$. The yolk sac membrane was disrupted with a homogenizer and filtered through a mesh strainer. Formalin $(0.3 \%)$ was used to inactivate Chlamydia with an equal volume of 206 adjuvant (SEPPIC, France) and mixed under $40 \mathrm{Mpa}$ of pressure. After 7 days of inactivation with formalin, the safety and efficacy of the vaccine were tested using specific pathogen free (SPF) embryos and mice (100-102).

Chlamydia inactivated vaccines for sheep and goat have been used since 1981-1986 (100). During that time, 120,000 sheep and goats in Qinghai, Gansu province, and Xinjiang Uygur Autonomous region were vaccinated and the abortion rate declined sharply. No abortion happened due to vaccination in pregnant sheep and goats. A total of 2,000,000 $\mathrm{ml}$ (about 700,000 doses) of inactivated vaccine was produced and used in 1988 (100). The duration of immunity was at least 2 years, but $75 \%$ of the sheep and goats were protected from infection in the 4 th year after vaccination $(100,103)$. Besides, the inactivated vaccine could be used after a 2 year storage period at $4^{\circ} \mathrm{C}(100)$. A similar inactivated vaccine of Chlamydia isolated from goat was studied by Zhang in the Inner Mongolia Autonomous Region (33). According to this report, 5,099 goats belonging to 51 groups were vaccinated with inactivated vaccine and at least $90 \%$ of the goats were protected. Other regions, such as Huachi County, Gansu province, showed similar results of very high prevalence of Chlamydia in goats during 1981-1986, with abortion rate in goats being $20-40 \%$. The disease was controlled when inactivated vaccine was used, reducing the abortion rate of the vaccinated groups to $3.3-6.5 \%$, compared with the control group abortion rate of 14.03-14.3\%, during 1986-1988 (102).

Chlamydia of swine was also detected and isolated in Qinghai province and the GuangxiZhuang Autonomous Region (55, 56, 88). According to these reports, abortion happened among sows and the highest positive rate of abortion was $56.1 \%$ in one of the groups in which Chlamydia was detected using the complement fixation test (CFT). Two strains were isolated using 7-day-old SPF eggs, and the inactivated vaccine was produced and tested (101). A total of 1,080 sows were vaccinated in two farms and each sow was immunized subcutaneously with $3 \mathrm{ml}$ of inactivated vaccine (101). After 3 months, 482 sows that had been vaccinated and 439 sows that were not vaccinated were studied; only $1.45 \%$ abortion rate was observed in the vaccinated group, while $29.53 \%$ abortion rate was observed in the non-vaccinated group (101). These results showed that the inactivated vaccine provided good infection protection (101). Subsequently, 10,594 sows were vaccinated in Qinghai, Shanxi province, and Guangxi Zhuang Autonomous regions. The duration of immunity was at least 1 year when $2 \mathrm{ml}$ of vaccine was injected (104). The vaccine remained active after storage at $4-8^{\circ} \mathrm{C}$ for 1 year (101).

Chlamydia in bovines was reported firstly in China in 1986 (70). In 1990, 2 strains (CCS10 and CCS15) were isolated from cows in a farm in Shaanxi province (105). However, the strain used for the inactivated vaccine was isolated in 2006 (102). This isolated strain (SX5) from a farm in Shaanxi province was tested and the $\mathrm{LD}_{50} / 0.4 \mathrm{ml}$ remained at $10^{-12}$ after at least 5 times propagation in SPF eggs. The minimal effective dosages for the vaccine was $3 \mathrm{ml}$ for adult dairy cow and $1.5 \mathrm{ml}$ for calf. The average protection was about $94.4 \%$, while the duration of immunity was 10 months (102).

Although formalin-inactivated $C$. abortus vaccines have been used in China since 1985, their production was discontinued because of lack of good manufacturing practices (GMP), causing 
sporadic outbreaks in sheep (46), yaks (106), and other animals. However, there is no information about Chlamydia prevalence in recent years from Dulan county (100), Delingha (56), Qinghai province, and Huachi county (101), Gansu province, where Chlamydia was first isolated and animals were vaccinated with inactivated vaccine. On the contrary, farms near the original places, such as in Wulan county, Guinan county, Haiyan county, Gonghe county, Huzhu county, Huangyuan county, and Tianjun County, Qinghai province, reported that Chlamydia caused huge abortion among sheep, goats, and yaks in recent years $(11,35,38,68,75$, $84,87,107-109)$. Interestingly, during the investigation, shepherds reported that dead Tibetan antelopes were found and their eyes were obviously blind (personal communication). They also reported that Chlamydia spread among different groups of sheep that had never been in contact with each other, suggesting that wild animals may play a very important role to spread Chlamydia to domestic animal. Therefore, based on this information, we can conclude that the original source of Chlamydia infections in China is wild animals in Qinghai province.

Besides inactivated vaccine, the subunit vaccine for Chlamydia in ewes, which has three different doses of major outer-membrane protein from genetically engineered Chlamydia psittaci, was developed by the State Key Laboratory of Pathogen and Biosecurity, Institute of Microbiology and Epidemiology, Academy of Military Medical Sciences, China. The study analyzed the antibody responses in ewes vaccinated with the subunit vaccine of rCps-MOMP. The sera of ewes were detected before vaccination and at different times post-vaccination. Experimental results indicated that multilocus intramuscular injection in the neck region with a dose of $0.5 \mathrm{mg}$ per ewe could stimulate good immune response (110). Because of the good security and immunity protection, a new veterinary drug certificate was awarded by the Ministry of Agriculture of the People's Republic of China (111). However, there are few reports of the promotion and application of the submit vaccine in China (112).

Although some successes were obtained for controlling Chlamydia in livestock in China since the inactivated vaccines were introduced, each year huge economic losses are caused by avian Chlamydia in chicken production (28). A subunit vaccine and a recombinant adenovirus live vector vaccine have been developed $(16,113)$. However, the recombinant adenovirus vector vaccine has not been approved by the government due to potential biological concerns, and no further data about the subunit vaccine has been published. Avian Chlamydia is still serious in China due to a lack of effective and safe vaccine. Moreover, the disease is a potential risk for human health. Therefore, further investigation into the development of vaccines is necessary.

\section{TREATMENT}

Antibiotics such as tetracycline, oxytetracycline, and penicillin sodium are used to treat Chlamydiosis in animals in China. However, since 2014, to regulate the use of veterinary antibiotics in China, the government established a veterinary prescription drug management system, including measures for administration of veterinary prescription and over-the-counter drugs. The quality of antibacterial drug products has been improving every year. The quality of sampling inspection is maintained at more than $95 \%$, whereas the rate of residues of veterinary drugs in livestock and poultry products remains stable at more than $97 \%$. Thus, the use of antibiotics has been greatly reduced.

\section{FUTURE PERSPECTIVE}

Although IHA plays a very important role in detecting Chlamydia in animals in China, it does not reflect the real situation of Chlamydiosis prevalence in animals. However, Hagemann JB (114) reported that aborting sheep exhibited a strong antibody response to surface (MOMP, MIP, and Pmp13G) and virulenceassociated (CPAF, TARP, and SINC) antigens. While the latter disappeared within 18 weeks following abortion in majority of the animals, antibodies to surface proteins persisted beyond the duration of the study. In contrast, experimental non-abortion infected sheep developed antibodies mainly to surface antigens (MOMP, MIP, and Pmp13G), all of which did not persist. This indicates that new diagnostic methods need to be established to improve the accuracy of disease diagnosis and provides scientific basis for controlling animal Chlamydiosis.

\section{CONCLUSION}

Since the first case of avian Chlamydia was reported in China, Chlamydia infection has been observed in different animals in most areas of China, which causes serious economic losses each year. Several diagnostic techniques, including CF, IHA, ELISA, ABC-ELISA, egg isolation, and PCR, have been studied and used in China. Formalin inactivated vaccines of Chlamydia from sheep, goat, swine, and cow were developed and have been used since 1981 in those areas where animals are threatened by Chlamydia. Because Chlamydiosis was considered an unimportant disease in animals by the Chinese government and no eradiation plan has implemented, there are sporadic outbreaks of Chlamydia in domestic animals in some areas, especially where vaccination has been suspended. However, the abortion rate was down sharply when inactivated vaccines for Chlamydia were used in domestic animals. This may have contributed to the lack of large-scale outbreak of Chlamydiosis in domestic animals in the last 30 years. The most important problem now is avian Chlamydiosis, which has a seropositive rate of $10-50 \%$ with IHA and easily spreads from birds to humans. Due to lack of effective vaccines, avian Chlamydiosis may become a public health problem in China.(Reorder)

\section{AUTHOR CONTRIBUTIONS}

Substantial contribution to the references of the work: ZLi, ZLou, YF. Draft and/or critical revision of the manuscript: JZ. Final approval of the version to be published: JZ, ZLi, ZLou, YF. 


\section{FUNDING}

This work was supported by the National Key Research and Development Plan (2017YFD0500905).

\section{REFERENCES}

1. Borel N, Polkinghorne A, Pospischil A. A review on Chlamydial diseases in animals: still a challenge for pathologists? Vet Pathol (2018) 1:300985817751218.

2. Dhama K, Chakraborty S, Tiwari R, Singh SD. Avian chlamydiosis (psittacosis / ornithosis): diagnosis, prevention and control, and its zoonotic concerns. Res Opin Anim Vet Sci (2013) 3(6):157-69.

3. Campos-Hernández E, Vázquez-Chagoyán JC, Salem AZ, Saltijeral-Oaxaca JA, Escalante-Ochoa C, López-Heydeck SM, et al. Prevalence and molecular identification of Chlamydia abortus in commercial dairy goat farms in a hot region in Mexico. Trop Anim Health Prod (2014) 46(6):919-24. doi: 10.1007/ s11250-014-0585-6

4. Yang XL, Zhang YX, Xu DT. Epidemiology investigationof Chlamydia abortus from sheep. Chinese J Vet Sci (1981) 7:13-15.

5. Aaziz R, Vorimore F, Verheyden H, Picot D, Bertin C, Ruettger A, et al. Detection of atypical Chlamydiaceae in roe deer (Capreolus capreolus). Vet Microbiol (2015) 181(3-4):318-22. doi: 10.1016/j.vetmic.2015.10.018

6. Szymańska-Czerwińska M, Mitura A, Niemczuk K, Zaręba K, Jodełko A, Pluta A, et al. Dissemination and genetic diversity of chlamydial agents in Polish wildfowl: Isolation and molecular characterisation of avian Chlamydia abortus strains. PLoS One (2017) 12(3):e0174599. doi: 10.1371/journal.pone. 0174599

7. Díaz JM, Fernández G, Prieto A, Valverde S, Lago N, Díaz P, et al. Epidemiology of reproductive pathogens in semi-intensive lamb-producing flocks in NorthWest Spain: a comparative serological study. Vet J (2014) 200(2):335-8. doi: 10.1016/j.tvjl.2014.02.022

8. Yang R, Jacobson C, Gardner G, Carmichael I, Campbell AJ, Ryan U. Longitudinal prevalence and faecal shedding of Chlamydia pecorum in sheep. Vet J (2014) 201(3):322-6. doi: 10.1016/j.tvjl.2014.05.037

9. Longbottom D, Entrican G, Wheelhouse N, Brough H, Milne C. Evaluation of the impact and control of enzootic abortion of ewes. Vet J (2013) 195(2):2579. doi: 10.1016/j.tvjl.2012.06.018

10. Wilson K, Sammin D, Harmeyer S, Nath M, Livingstone M, Longbottom D. Seroprevalence of chlamydial infection in cattle in Ireland. Vet J (2012) 193(2):583-5. doi: 10.1016/j.tvjl.2011.12.018

11. Li Z, Cao X, Fu B, Chao Y, Cai J, Zhou J. Identification and characterization of Chlamydia abortus isolates from yaks in Qinghai, China. Biomed Res Int (2015) 2015:1-6. doi: 10.1155/2015/658519

12. Vidal S, Kegler K, Greub G, Aeby S, Borel N, Dagleish MP, et al. Neglected zoonotic agents in cattle abortion: tackling the difficult to grow bacteria. BMC Vet Res (2017) 13(1):373. doi: 10.1186/s12917-017-1294-y

13. Mcewen AD, Foggie A. Enzootic abortion in ewes: prolonged immunity following the injection of adjuvant vaccine. Vet Rec (1956) 68:686-90.

14. Linklater KA, Dyson DA. Field studies on enzootic abortion of ewes in south east Scotland. Vet Rec (1979) 105(17):387-9. doi: 10.1136/vr.105.17.387

15. Pan DX. The research progress of Chlamydia trachomatis and psittaci in China. Chinese Journal Zoonoses (1987) 3(2):47-9.

16. Zhou J, Qiu C, Cao XA, Lin G. Construction and immunogenicity of recombinant adenovirus expressing the major outer membrane protein (MOMP) of Chlamydophila psittaci in chicks. Vaccine (2007) 25(34):6367-72. doi: 10.1016/j.vaccine.2007.06.031

17. Shuai YY, Huang MQ, Wn G, Cheng X, Yang XL. Study of Chlamydia abortus from sheep - pathogen isolation and identification. Chinese Journal Veterinary Science (1981) 8:1-5.

18. Lenzko H, Moog U, Henning K, Lederbach R, Diller R, Menge C, et al. High frequency of chlamydial co-infections in clinically healthy sheep flocks. BMC Vet Res (2011) 7:29. doi: 10.1186/1746-6148-7-29

\section{ACKNOWLEDGMENTS}

Special thanks to Xueli Yang, Yingcai Li, Yongyu Shuai, and Changqing Qiu who devoted their life to researching Chlamydia and controlling its prevalence in China.

19. Szymańska-Czerwińska M, Niemczuk K. Avian Chlamydiosis zoonotic disease. Vector Borne Zoonotic Dis (2016) 16(1):1-3. doi: 10.1089/vbz.2015.1839

20. Yu WJ, Ma WL, Zhu QT, Yang XJ, Wang WD. Studies on epidemiology,clinical symptoms and pathogenesisof chicken Chlamydiosis. Chinese Journal Veterinary Science Technology (1994) 24(2):13-15.

21. Shi Y, He C, Zhu H, Duan Q. Isolation and characterization of Chlamydia psittaci in broiler. Chinese Journal of Laboratory Animal Science (2003) 13(4):217-21.

22. Ou YP, Chen JJ, Sun M, He CL, Shu G, Ying ZQ. Isolation and characterization of Chlamydia psittaci isolated from broilers. Chinese Veterinary Science (2016) 46(01):46-51.

23. Wu FM, Li YL, Zhang JL. Detection of avian Chlamydiosis. Chinese Journal of Zoonoses (1990) 6(1):61.

24. Xu XP, Ma YL, Zheng AW, Wang Y, Fan QS. Serological investigation of Chlamydia psittacifrom chicken in part of Sichuan areas. Sichuan Animal \& Veterinary Sciences (1991) 01:18-19.

25. Wang CY, Wei YM. Investigation of Chlamydia from sheep and chicken in Zhangye area, Gansu province. Chinese Journal of Animal Health Inspection (1991) 04:18.

26. Wang QQ, Liu BS. Study on Chlamydiosis in chicks in Honghe district:isolation and identification of the causative agents and artificial infection test. Chinese Journal of Veterinary Science and Technology (1997) 27(3):10-12.

27. Jiang SZ, Zhang YQ, Hu YJ, Jiang YC, Yao XJ, Zhao YL. Investigation of Chlamydia psittaci from chicken in two farms of Mudanjiang area. Heilongjiang Animal Science and Veterinary Medicine (1998) 07:25-6.

28. Liu Q, Li HM, Guo JG. Serological investigation of flow Chlamydiosis. Poultry Husbandry and Disease Control (2001) 11:13.

29. Zhang JB, Lu YK, Cheng JH. Serological investigation of pigeon Chlamydiosis. Chinese Journal of Veterinary Medicine (2003) 39(6):29.

30. Ou CC, Pan L. Infection status investigation of Chlamydia psittaci from ducks in parts of Anhui area. China Poultry (2012) 02:61-3.

31. Ma YJ, Zhang LC. Serological investigation of Chlamydiosis in livestock and poultry in Qinghai Province. Chinese Veterinary Science (2013) 43(02):213-5

32. Zhu YN, Wang H, Lei LC. Epidemiological investigation of Chlamydia infection in Avian in Tianjin areas. Heilongjiang Animal Science and Veterinary Medicine (2016) 10:148-50.

33. Zhang BF, Zhao YF, Zhou ZX, Hu H, Zhao MX. Study on inactivated vaccine of Chlamydia abortus from goat. Chinese Journal of Animal and Poultry infections diseases (1987) 01:18-20.

34. Li ZJ, Wang QF, Fang CX, Chen MG, Wu BR, Wang YN. Immunoprophylaxis of goat chlamydia abortion in Huachi County. Chinese veterinary technology (1990) 06:24-6.

35. Su BH. Study on serological of Chlamydia in sheep and cows in Gonghe County. Chinese Qinghai Journal of Animal and Veterinary Science (2016) 46(3):29-30.

36. Wu LJ, Liu Q, Zheng LF, Chen ZX, Teng BZ. Seroprevalence investigation of Chlamydia abortus from goats in Guangxi, China. Chinese Journal of Veterinary Science and Technology (2000) 30(9):41.

37. Hong NN, Yan XG, Pi Q, Hua Y, Li JZ. Serological survey for Chlamydia antibodies in cattle and goats in Guizhou Province. Progress in Veterinary Medicine (2012) 33(11):127-9.

38. Zha XC. Study on serological of Chlamydia in sheep and cows in Gonghe County. Shandong Journal of Animal Science and Veterinary Medicine (2017) 38(10):60-1.

39. Wang XN, Zhao GY. Seroprevalence investigation of Chlamydia abortusfrom sheep in Zhejiang Province. Vet Sci China (1990) 20(8):11.

40. Zhang XZ, Zheng GS, Gen XQ. Investigation of Chlamydia abortus from sheep in XiangFan, Bubei province. Chinese Journal of Zoonses (1992) 8(1):34. 
41. Qiu CQ, Zhou JZ, Gao SD, Cheng SM, Duan YJ, Li YC. Monitoring of swine chlamydiosis on partial intensive pig farms in six Province. Chinese Journal of Veterinary Science and Technology (1998) 28(10):3-5.

42. Wang QQ, Zhang JW, Zhang RH. Investigation of Chlamydiosis from domestic animal in Honghe state, Yunnan Province. Chinese Journal of preventive veterinary medicine (2000) 22(6):465-6.

43. Bao JM, He CL, Xu B, Lv JM, Ma Q. Serological investigation of Chlamydia abortus from large scale breeding sheep in Ningxia Hui autonomous region. Gansu Animal and Veterinary Sciences (2003) 33(4):13-14.

44. Wang L, Sun CC, Sui LY, Tang KB, Wang XF, Wang GY. Serological investigation of Chlamydia abortus from sheep in Hulunbeier, the NeiMonggol autonomous region. Animal Husbandry and Feed Science (2009) 31(1):154.

45. Lei CH, Guo FL, Guo QY, Shuan Z, Lv CH, Huang YB. Serological investigation of Chlamydia abortus and Mycoplasma from sheep. Xinjiang Journal of Animal Husbandry (2012) 7:28-9.

46. Huang SY, Wu SM, Xu MJ, Zhou DH, Danba C, Gong G, et al. First record of Chlamydia abortus seroprevalence in Tibetan sheep in Tibet, China. Small Ruminant Research (2013) 112(1-3):243-5. doi: 10.1016/j. smallrumres.2012.12.012

47. Zhang LC, Wang XZ, Zhang MH, La H, You XQ. Serological investigation of Chlamydiosis in livestock in Qinghai province. Chinese Journal of Veterinary Medicine (2014) 50(4):38-9.

48. Cheng WW, Peng JW, Zhang KS. Surveillance and analysis of Chlamydia seroprevalence from goat and sheep in some regions, China. Chinese Journal of Zoonnoses (2015) 31(5):472-4.

49. Gao JY, Hu JX, Li C. Detection and analysis of goat Chlamydiosis in part of Xinyang area in Henan province. Acta Ecologiae Animalis Domastici (2017) 38(1):66-9.

50. Jiang TT, Yang YS, Meng QY, Fang YL, Han SL. Serological investigation of Chlamydia from swine with HIA. Hubei Journal of Animal and Veterinary Sciences (1985) 6(4):32-4.

51. Suo XF, Wang DL, Zhang CH. The epidemiology investigation of serological from large scale swine farm in Hainan province. Swine Production (2005) 3:31-2.

52. Bi JL, Yang B, Gao LB, Yang GS, Tai XY, Yin GF. Serological invetigation on porcine Choamydiae infection in Yunnan Province. Progress in Veterinary Medicine (2011) 3:134-6.

53. Su YS, Zhu LY, Li PD, Zhao Q. Serological survey of porcine Chlamydiae infection in parts of Chuxiong prefecture in Yunnan Province. Journal of Anhui Agriculture Science (2015) 43(16):155-6.

54. Ma CF, Gao JY, Hu JX, Li H, Ma Y, Xu YJ. Seral antibody detection of Chlamydia in breeding Swine herds in Xingyang of Henan province. Progress in Veterinary Medicine (2016) 37(10):119-22.

55. Yi QZ, Zheng LF, Cheng ZX, Zhou GJ, Pang BH, Liu Q. Isolation and characterization of Chlamydia abortus from swine in Guang Xi Zhuang autonomous region. Guangxi Journal of Animal Husbandry \& Veterinary Medicine (1991) 2:6-9.

56. Diao YX, Gl Y, Zhao YX, Li XF, Ga QJ, Jiao HZ. Diagnosis and preventing of Chlamydia abortus in animal from Delinha farm, Qinghai province. Chinese journal of veterinary science and technology (1990) 3:21-2.

57. Ji RG, Fan WX. Serological investigation of Chlamydia in swine. Shandong Journal of Animal Husbandry and Veterinary Science (2003) 24(1):39.

58. Gao SZ, Wei RS, Shi YN, Shu Z, Han QY, He HC. Serological investigation of Chlamydia from swine in Gansu Province. Gansu Animal and Veterinary Sciences (2001) 33(2):13-14.

59. Lang LM, Wang KL, Xiong HD, You G, Zhang B. Serological investigation of Chlamydia in infected swine in Henan Province. Swine Production (2004) 19(4):29.

60. Wang HZ. Serological investigation of Chlamydia from swine of large scale breeding farm. Modern Journal of Animal Husbandry and Veterinary Medicine (2004) 33(11):26.

61. Jin AH, Gu BL, Wei XY, Fang GM. Serological investigation of Chlamydia from swine in Shanghai and surrounding areas. Shanghai Journal of Animal Husbandry and Veterinary Medicine (2005) 50(6):23.

62. Zhu YQ, Wang RB, Cai YQ, Hu JC, Lai XX. Serological investigation of Chlamydiosis from swine. Guangdong Journal of Animal and Veterinary Science (2007) 32(4):26-7.
63. Zhou P, Lin ZY, Wang TF, Luo CQ, Qiu SS, Zhang HQ. Investigation on sera epidemiolog of porcine chlamydiosis in several regions of Longyan city. Progress in Veterinary Medicine (2008) 29(7):30-5.

64. Wang JQ, Wei H, Wang WH, Ma NJ. Seroprevalence investigation of reproductive obstacle disease from sow. Contemporary Animal Husbandry (2013) 41(15):9-10.

65. Jiang HH. Serological investigation of Toxoplasmosis and Chlamydiosis in pigs in Jiangxi Province and genotyping of Toxoplasma gondii from pigs from different localities in China. The Chinese Academy of Agricultural Sciences (2014):27-8.

66. Li YL. Serological survey of porcine Chlamydiae infection in parts of Chuxiong prefecture in Yunnan Province. Veterinary science and technology (2014) 33:29-30.

67. Zhou JZ, Qiu CQ, Cheng SM, Gao SD. Serological study of Chlamydiosis in meat cattle at the partial areas in China. Chinese Journal of Veterinary Science and Technology (2000) 30(7):14-15.

68. Xie Q, Zeng J, Zhao XR, Wu E, Wang N. The Chlamydia abortus isolation and identification from cow in Ning Xia Hui autonomous region, China. Heilongjiang Animal Science and Veterinary Medicine (2012) 05:102-4.

69. Wang WY, Xie AM, Lin YQ, Shen YL, Cai JS. Study on serological of Chlamydia in cows in Huzhu County. Chinese Qinghai Journal of Animal and Veterinary Science (2016) 46(3):16-17.

70. Yang YS, Jiang TT, Fang YL, Meng QY, Tan HY, Yong Z. Diagnosis report of mixed infection with cow Chlamydiosis and brucellosis. Hubei Journal of Animal and Veterinary Sciences (1986) 04:4-9.

71. Li F, Zhang DM, Liang ZM. Serological investigation of Chlamydiosis of cows in partial dairies in Henan Province. Journal of Agricultural Catastrophology (2017) 7(2):22-4.

72. Yang YS, Jiang TT, Fang YL, Meng QY, Tan HY, Yong Z. Diagnosis report of mixed infection with cow Chlamydiosis and brucellosis. Chinese Journal of Veterinary Medicine (1988) 14(9):5-6.

73. Huo BN. Serological investigation and control of Chlamydia abortus and Brucella from cows. Livestock and Poultry Industry (2013) 24(6):67.

74. Tan QD, LI, ZX, Wang XL, Yin MY, Qin SY, Liu GX. Seroprevalence investigation and risk ractors analysis of Chlamydia infection in dairy cattle in Gansu and Ningxia areas. Vet Med (2015) 42(5):1283-7.

75. Chen CJ, Fan XL, Tan ML. Serological survey and analysis on Brucella, Chlamydia, and Toxoplasmosis on scale dairy farming in Huangyuan county of Qinghai. Chinese Qinghai Journal of Animal and Veterinary Science (2017) 47(1):33-5.

76. Shuai YY, Yc L, Dan K, Duan YJ, Cheng GL, Yang ZP. Diagnosis of enzootic abortion in yak. Scientia Agriculture Sinica (1988) 21(4):76-81.

77. Wang GH, Shi BX, Ma XG. Serological investigation of Chlamydiosis in Yaks. Grass-feeding Livestock, Grass-feed Lives (1996) 03:46.

78. Hou SK. Serological investigation of Chlamydiosis in Yaks in Guoluo areas of Qinghai province. Chinese Qinghai Journal of Animal and Veterinary Science (2011) 41(04):10.

79. Qin SY, Huang SY, Yin MY, Tan QD, Liu GX, Zhou DH, et al. Seroprevalence and risk factors of Chlamydia abortus infection in free-ranging white yaks in China. BMC Vet Res (2015) 11:8. doi: 10.1186/s12917-015-0323-y

80. Dong CX, Bu D, Ban JM. Serological investigation of Chlamydiosis in Yaks in Guoluo areas of Qinghai province. Chinese Qinghai Journal of Animal and Veterinary Science (1993) 02:25.

81. Ma SL, Li XH, Lu Y, Yang QY, Pen XX, Ma DK. Serological investigation of Chlamydiosis in Yaks in Qinghai province. Chinese Qinghai Journal of Animal and Veterinary Science (2004) 34(5):14.

82. Zhang XQ, Li WC, Wan MDZ, Lu Y. Investigation and analysis of Chlamydiosis in Yaks in Tianjun areas of Qinghai province. Gansu Animal Science and Veterinary Medicine (2009) 39(03):14-15.

83. Kong XY, Bao SK, He CJ. Serological investigation of Chlamydiosis and Brucella in Yaks in Qinghai Lake areas. Animals Breeding and Feed (2012) 11:51-2.

84. Li JH, Zhang XQ, Li WC, Zhou JZ. Serological investigation of Chlamydiosis and Brucella in Yaks in Tianjun areas of Qinghai province. Animal Husbandry \& Veterinary Medicine (2013) 45(7):126.

85. Xie ZX. Epidemic dynamic investigation of Chlamydiosis in Yaks in Guoluo areas of Qinghai province. Chinese Qinghai Journal of Animal and Veterinary Science (2013) 43(1):33. 
86. Yin MY, Tan QD, Qin SY, Liu GX, Zhu XQ, Zhou DH. Seroprevalence of Chlamydia Infection in Yaks in Gansu Province. Journal of Animal Science and Veterinary Medicine (2014) 41(10):281-5.

87. Fu YG, Chao YL, Chang MH. Investigation and analysis of Chlamydiosis in yaks and Tibetan sheep in Qinghai province. Chinese Journal of Veterinary Medicine (2016) 52(9):50-1.

88. Yang YS, Jiang TT, Men QY. Studies on indirect hemagglutinationtest (IHA) to determine against Chlamydia antibodies Chinese. Journal of Animal and Veterinary Sciences (1984) 15(3):181-7.

89. Ge WN, Shuai YY, Dan K, Li YC, Yang ZP, Yang XL. Study on antibody of Chlamydia abortus detected by ELISA. Chinese Journal of Veterinary Science and technology (1986) 04:16-19.

90. Yang ZP. An ABC-ELISA for detecting antibodies against abortigenic Chlamydiae in sheep and goats. Chinese Journal of Zoonses (1990) 2:38-41.

91. Yang X, Shuai YY, Ge WN, Huang MQ, Li YC, Cheng ZT. Isolation of Chlamydia abortus from sheep. Chinese Journal of Veterinary Science and Technology (1984) 2:83-9.

92. Okuda H, Ohya K, Shiota Y, Kato H, Fukushi H. Detection of Chlamydophila psittaci by using SYBR green real-time PCR. J Vet Med Sci (2011) 73(2):24954. doi: 10.1292/jvms.10-0222

93. Wittenbrink MM, Schoon HA, Schoon D, Mansfeld R, Bisping W. Endometritis in cattle experimentally induced by Chlamydia psittaci. Zentralblatt Veterinarmedizin Reihe B (1993) 40(6):437-50. doi: 10.1111/j.1439-0450.1993. tb00161.x

94. Kaltenboeck B, Kousoulas KG, Storz J. Two-step polymerase chain reactions and restriction endonuclease analyses detect and differentiate ompA DNA of Chlamydia spp. J Clin Microbiol (1992) 30(5):1098-104.

95. Gutierrez J, O’Donovan J, Proctor A, Brady C, Marques PX, Worrall S, et al. The application of the policy real-time polymerase chain reaction for the diagnosis of toxoplasmosis and enzootic abortion of ewes. J Vet Diagn In Vest (2012) 24(5):846-54. doi: 10.1177/1040638712452730

96. Thiele D, Wittenbrink MM, Fischer D, Krauss H. Evaluation of the polymerase chain reaction (PCR) for detection of Chlamydia psittaci in abortion material from ewes. Zentralbl Bakteriol (1992) 277(4):446-53. doi: 10.1016/S09348840(11)80469-X

97. Mi ZH, Qin L. Study on detection methods of Chlamydia psittaci by nested PCR and DNA sequencing analysis. Chinese Journal of zoonoses (2002) 18(3):68-70.

98. Fei YY, Li ZC, Lou ZZ. Detection of Chlamydia in livestock by recombine polymerase amplification. Chinese Veterinary Science (2018) 48(02):142-7.

99. Chen Q, Gong X, Zheng F, Cao X, Li Z, Zhou J. Seroprevalence of Chlamydophila abortus infection in yaks (Bos grunniens) in Qinghai, China. Trop Anim Health Prod (2014) 46(3):503-7. doi: 10.1007/s11250-013-0519-8

100. Shuai YY, Li YC, Yang ZP, Dan K, Cheng GL, Duan YJ. Study on yolk sac membrane methanol killing and oil adjuvant vaccine of Chlamydia abortus in sheep. Chinese journal of veterinary science and technology (1989) 11:3-6.

101. Li ZJ, Wang QF, Fang CX, Chen MG, Wu BR, Wang YN. Immunization test of Chlamydia abortus vaccine from goats in Huachi County, China. Chinese journal of veterinary science and technology (1990) 06:24-6.
102. Qiu CQ, Zhou JZ, Cheng SM, Cao XA. Identification and immunogenicity of pathogen causing Chlamydial abortion in dairy cows. Vet Sci China (2006) 04:270-3.

103. Foggie A. The duration of immunity in ewes following vaccination against ovine enzootic abortion virus. Vet Rec (1959) 71:741-2.

104. Li YC, Shuai YY, Duan YJ, Gao SD, Yang XL, Qiu CQ. Study on inactivated vaccine of Chlamydia abortus in pigs. Chinese journal of veterinary science and technology (1995) 25(11):3-7.

105. Lin ZY, Huang MR, Zhang ZZ, Liang DJ, Li YC, Duan YJ. The isolation and identification of Chlamydia abortus in cow. Chinese journal of veterinary science and technology (1992) 02:27-30.

106. Gao LY, Zhang DH, Wang QJ, Pu ZZ, Chen DT. The seroprvevalence investigation of Chlamydia in yaks in Tianjun County. China Shanghai Journal of Animal Husbandry and Veterinary Medicine (2013) 01:3.

107. Zhang XQ, Li WC. Seroprevalence investigation of Chlamydia abortus in Tibetan sheep in Tianjun County, Qinghai province. Chinese Journal of Veterinary Medicine (2011) 10:45.

108. Zhang YL, Li CH. Seroprevalence investigation of Chlamydia in yaks and sheep in HaiYan County, China. Heilongjiang Animal Science and Veterinary Medicine (2011) 6:79-80.

109. Zhang YL. Seroprevalence investigation of Chlamydia in yaks and sheep in WuLan County, Qinghai province. Heilongjiang Animal Science and Veterinary Medicine (2012) 2:88-9.

110. Li YW, Yang BF, Song LH, M, GH, Zhu H, Duan Q. Kinetics curve of antibody responses in ewes immunized with subunit vaccine of genetically engineered Chlamydia psittaci. Chinese Journal of Zoonoses (2010) 26(9):835-7.

111. Zhu WG, Zheng J, Lianx Z, Cui J, Xie Q. The research progress of animal chlamydia vaccine. Modern Journal of Animal Husbandry and Veterinary Medicine (2015) 9:41-5.

112. Zhang ZJ, Zhou JZ. Progress on Chlamydia abortus. Progress in Veterinary Medicine (2017) 38(4):102-7.

113. He C, Zhu H, Wang CW, He J, Zhang HJ, Tan H. Investigation on immune response in broiler immunized with recombinant major outer-membrane protein of Chlamydia psittaci. J China Univ Geosci (2004) 01:45-8.

114. Hagemann JB, Simnacher U, Longbottom D, Livingstone M, Maile J, Soutschek E, et al. Analysis of humoral immune responses to surface and virulenceassociated Chlamydia abortus proteins in ovine and human abortions by use of a newly developed line immunoassay. J Clin Microbiol (2016) 54(7):188390. doi: 10.1128/JCM.00351-16

Conflict of Interest Statement: The authors declare that the research was conducted in the absence of any commercial or financial relationships that could be construed as a potential conflict of interest.

Copyright $(0) 2018$ Zhou, Li, Lou and Fei. This is an open-access article distributed under the terms of the Creative Commons Attribution License (CC BY). The use, distribution or reproduction in other forums is permitted, provided the original author $(s)$ and the copyright owner are credited and that the original publication in this journal is cited, in accordance with accepted academic practice. No use, distribution or reproduction is permitted which does not comply with these terms. 